\title{
Sintesis Karbon Aktif dari Kulit Pisang untuk Pemurnian Air Tambang Emas dari Logam Berat di Sungai Batang Palangki Kabupaten Sijunjung
}

\author{
Rahmah Khairati Maiza, ${ }^{*}$ Melanz Hasan, Muhammad Fadly, dan Astuti \\ Jurusan Fisika, Universitas Andalas (UNAND), Jl. Limau Manis, Padang 25163
}

Intisari

\begin{abstract}
Telah dilakukan pemurnian limbah air galian tambang emas dari logam berat di sungai Batang Palangki Kabu-paten Sijunjung. Sebelum dilakukannya pemurnian limbah air ini, sampel air terlebih dahulu diukur kadar logam beratnya menggunakan Inductively Coupled Plasma (ICP) dan ditemukan 24 unsur logam yang mana 8 diantaranya di atas ambang batas syarat baku mutu air bersih. Pemurnian air menggunakan teknik adsorbsi dengan adsorben karbon aktif dari kulit pisang kepok. Penelitian ini menggunakan karbon aktif dengan vari-asi konsentrasi aktivator $\mathrm{H}_{2} \mathrm{SO}_{4} 20 \%, 25 \%, 30 \%$, dan 35\%. Karbon aktif ditambahkan ke dalam gelas ukur yang berisi $100 \mathrm{ml}$ limbah air galian tambang emas, diaduk hingga homogen dan dibiarkan mengendap ke dasar gelas ukur, lalu air disaring menggunakan kertas saring, diukur $\mathrm{pH}$, kadar logam berat dan nilai konduktivitas listriknya. Berdasarkan hasil penelitian, karbon aktif dengan penyerapan yang paling optimal yaitu pada konsentrasi 35\% dengan ukuran pori karbon aktif rata-rata sebesar 24,6 $\mu \mathrm{m}$. Data ini diperoleh dari alat ICP dengan membandingkan kadar logam berat air limbah sebelum dan sesudah perlakuan karbon aktif. Air yang dimurnikan sudah sesuai dengan peraturan Menteri Kesehatan No. 416/MENKES/PER/IX/1990 tentang persyaratan kualitas air bersih dan Peraturan Pemerintah No. 82 Tahun 2001 tentang Pengelolaan Kualitas Air dan Pengendalian Pencemaran Air.
\end{abstract}

\begin{abstract}
The purification of wastewater from the gold mine from heavy metals in Batang Palangki, Sijunjung Regency has been carried out. Prior to the purification of this wastewater, water samples were first measured by heavy metal content using Inductively Coupled Plasma (ICP) and found 24 heavy metal elements of which 8 of them were above the standard threshold of water quality standards. Purification of water using adsorption technique with adsorbent activated carbon from banana kepok skin. This study used activated carbon with concentration concentration of $20 \%, 25 \%, 30 \%$, and $35 \% \mathrm{H}_{2} \mathrm{SO}_{4}$ activator. Activated carbons were added to the measuring cup containing $100 \mathrm{ml}$ of gold mine wastewater, stirred to homogeneous and allowed to settle to the bottom of the measuring cup, then filtered water using filter paper, measured $\mathrm{pH}$, heavy metal content and electrical conductivity values. Based on the research results, activated carbon with the most optimal absorption is at a concentration of $35 \%$ with the average pore size of activated carbon of $24.6 \mu \mathrm{m}$. This data was obtained from the Inductively Coupled Plasma (ICP) tool by comparing the heavy metal content of wastewater before and after the activated carbon treatment. The purified water is in accordance with Minister of Health Regulation no. 416 / MENKES / PER / IX / 1990 on water quality requirements and Government Regulation no. 82 of 2001 on the Management of Water Quality and Control of Water Pollution.
\end{abstract}

Keywords: Heavy metals; banana peels; purification.

http://dx.doi.org/10.12962/j24604682.v15i1.3815

2460-4682 @Departemen Fisika, Fakultas Sains-ITS

\section{PENDAHULUAN}

*Electronic address: rahmahkhairati@gmail.com
Pencemaran logam berat berbahaya bagi kehidupan tanaman, binatang, kesehatan manusia, dan menyebabkan kerusakan ekosistem. Logam berat dapat masuk melalui kulit, saluran pernapasan dan pencernaan [1]. Logam berat memiliki pengaruh yang berbeda jika terakumulasi dalam tubuh manusia [2]. Racun yang dimiliki logam berat akan 


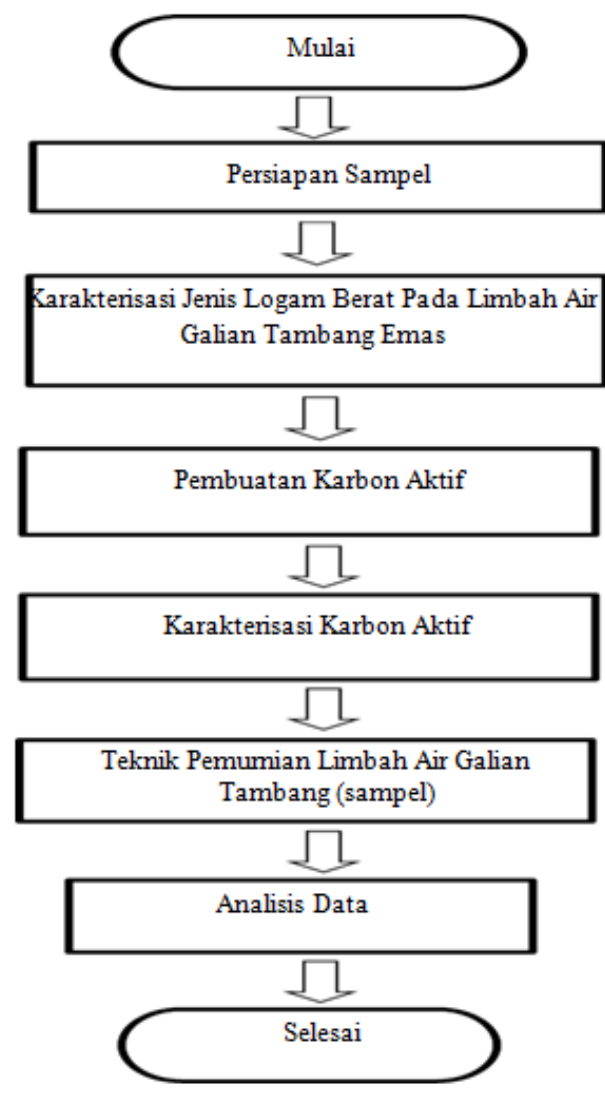

Gambar 1: Diagram alir tahapan penelitian.

bekerja sebagai penghalang kerja enzim, sehingga proses metabolisme terputus dan juga sebagai penyebab alergi, mutagen dan karsinogen bagi manusia.

Salah satu cara pemurnian air untuk menurunkan kadar logam berat ialah dengan teknik adsorbsi. Adsorben yang digunakan pada penelitian ini adalah karbon aktif dari kulit pisang kepok. Kulit pisang kepok dipilih sebagai karbon aktif karena kulit pisang juga memiliki kandungan karbon yang banyak dan daya serap yang bagus [3]. Kulit pisang kepok mengandung beberapa komponen biokimia, antara lain selulosa, hemiselulosa, pigmen klorofil dan zat pektin yang mengandung asam galacturonic, arabinosa, galaktosa, selulosa dan rhamnosa. Asam galacturonic menyebabkan kulit pisang kuat untuk mengikat ion logam.

Komponen-komponen struktural utama kulit pisang adalah selulosa sekitar $75 \%$, lignin sekitar $20,21 \%$, dan serat seki$\operatorname{tar} 5,1 \%$. Lignin adalah material yang mengandung karbon relatif tinggi dibandingkan dengan selulosa dan hemiselulosa. Selain itu aktivasi secara kimia menggunakan $\mathrm{H}_{2} \mathrm{SO}_{4}$ mempunyai peran dalam memperbesar karakteristik luas permukaan karbon aktif sehingga daya serapnya lebih besar.

Pada penelitian ini dilakukan penyerapan logam berat dalam air limbah galian tambang emas menggunakan karbon aktif dari kulit pisang kepok. Pemanfaatan limbah kulit pisang kepok sebagai karbon aktif akan mengurangi kadar logam berat yang terkandung pada air limbah galian tambang emas agar sesuai syarat air layak guna kelas II sehingga air dapat di- gunakan dengan layak oleh masyarakat. Penelitian ini juga memvariasikan konsetrasi larutan activator $\mathrm{H}_{2} \mathrm{SO}_{4}$ sebanyak $20 \%, 25 \%, 30 \%$ dan $35 \%$ untuk melihat struktur pori dan daya serap dari karbon aktif.

\section{METODOLOGI PENELITIAN}

Metode yang dilakukan pada penelitian ini dapat dilihat pada Gambar 1. Sampel limbah air galian tambang emas dikarakterisasi menggunakan Inductively Coupled Plasma (ICP) untuk mengetahui jenis dan kadar logam berat yang terdapat pada air limbah tersebut. Pembuatan karbon aktif diawali dengan mencacah kulit pisang, lalu dibiarkan di udara terbuka. Setelah itu kulit pisang diarangkan dengan menggunakan furnace temperature $400^{\circ} \mathrm{C}$ selama 1,5 jam. Kemudian arang digerus dan direndam dengan aktivator $\mathrm{H}_{2} \mathrm{SO}_{4}$ sebanyak $30 \mathrm{~g}$ untuk diaktivasi secara kimia selama 24 jam dengan variasi konsentrasi sebesar 20\%, 25\%, 30\% dan 35\% dengan masing-masing nilai konsentrasinya $\mathrm{H}_{2} \mathrm{SO}_{4}$ pekat antara lain $31,25 \mathrm{ml}, 39,06 \mathrm{ml}, 46,87 \mathrm{ml}$ dan 54,68 $\mathrm{ml}$ yang sudah dicampurkan $100 \mathrm{ml}$ aquades. Setelah itu, karbon aktif dipanaskan menggunakan furnace untuk diaktivasi secara fisika dengan temperatur yang digunakan $400^{\circ} \mathrm{C}$ selama 2 jam. Karbon aktif yang telah diaktivasi secara fisika dicuci dengan aquades hingga $\mathrm{pH}$ dari filtratnya netral. Lalu, karbon aktif dikeringkan lagi dengan oven temperatur $120^{\circ} \mathrm{C}$ selama 30 menit. Setelah itu, karbon aktif dikarakterisasi menggunakan Scanning Electron Microscopy (SEM) untuk melihat pori pada karbon aktif.

Pengujian air tambang dilakukan dengan, mencampurkan $5 \mathrm{~g}$ ke dalam $100 \mathrm{ml}$ air tambang dan diaduk sampai rata. Setelah itu sampel air disaring menggunakan kertas saring dan diukur $\mathrm{pH}$ nya menggunakan kertas $\mathrm{pH}$, sedangkan kadar logam berat diukur menggunakan ICP dan nilai konduktivitas listrik diukur menggunakan konduktivitimeter.

\section{HASIL DAN PEMBAHASAN}

Hasil pada Tabel I memperlihatkan konsentrasi logam berat yang berada di atas batas ambang aman untuk persyaratan kualitas air bersih. Batas ambang ini mengacu pada peraturan Menteri Kesehataan No 416/MENKES/PER/IX/1990 dan Peraturan Pemerintah no. 82 tahun 2001. Sebelumnya, sampel air diukur nilai $\mathrm{pH}$ nya sebesar 4. Setelah diberikan perlakuan karbon aktif $\mathrm{pH}$ dari air tersebut menjadi $\mathrm{pH} 7$. Hasil ini juga memperlihatkan penurunan kosentrasi logam berat setelah ditambahkan karbon aktif. Penurunan kosentrasi logam berat ini telah berada dibawah ambang batas persyaratan air bersih sehingga bisa dimanfaatkan untuk keperluan sehari-hari.

Gambar 2 merupakan hasil karakterisasi karbon aktif dari kulit pisang menggunakan Scanning Electron Microscopy (SEM) untuk melihat morfologi karbon aktif yang telah disintesis dari kulit pisang meliputi bentuk permukaan, ukuran, dan distribusi pori. 


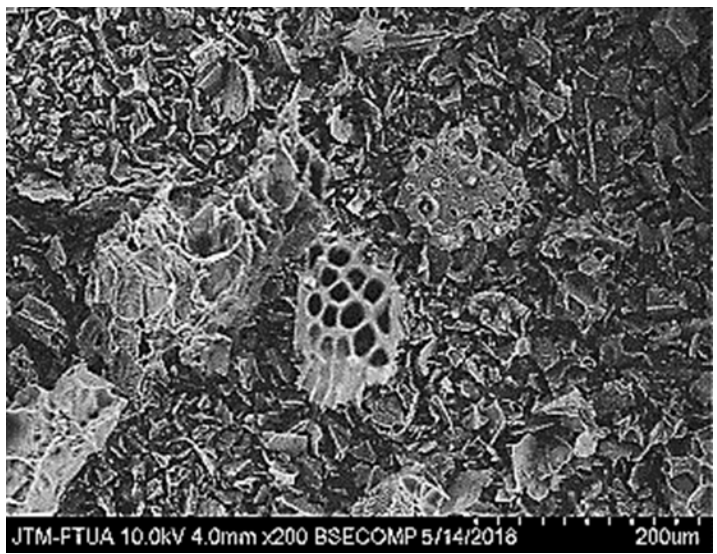

(a) $20 \%$

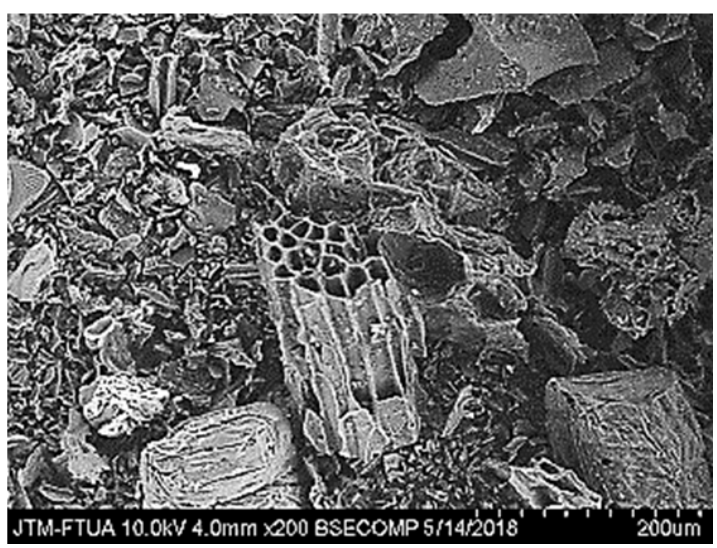

(c) $30 \%$

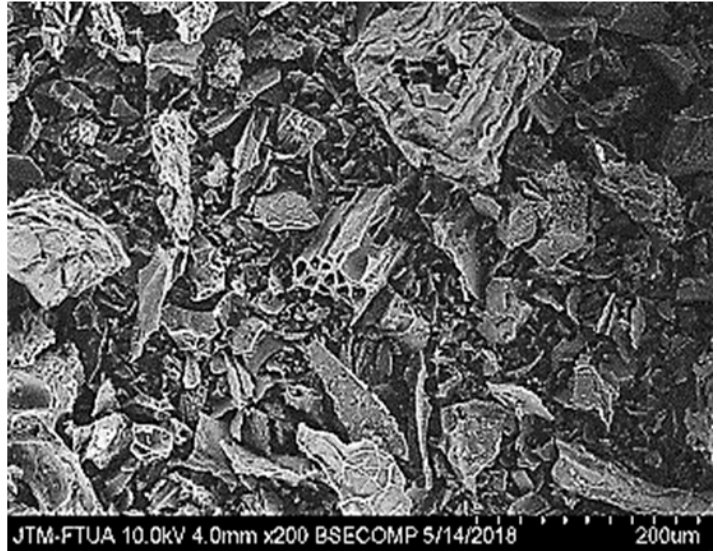

(b) $25 \%$

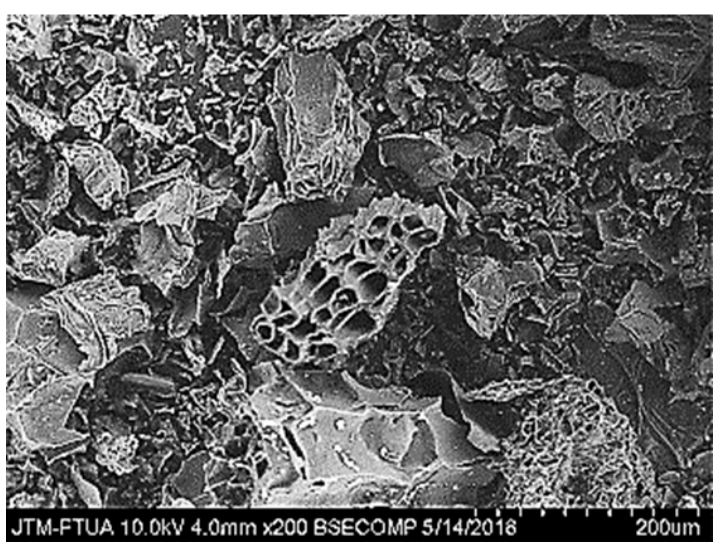

(d) $35 \%$

Gambar 2: Foto SEM untuk variasi konstrasi karbon aktif.

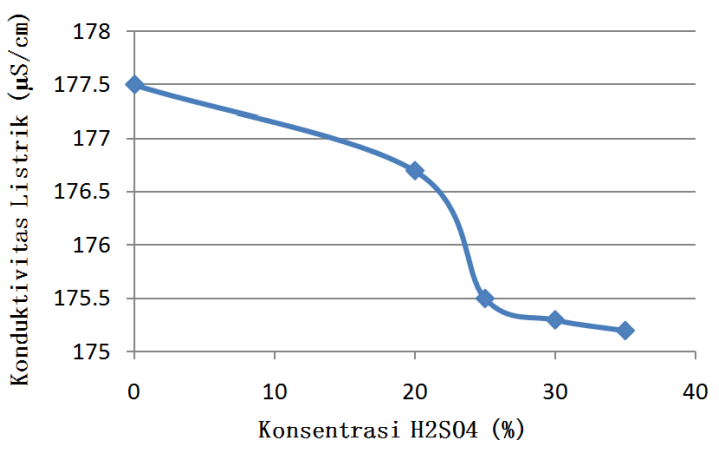

Gambar 3: Grafik perbandingan konsentrasi aktivator $\mathrm{H}_{2} \mathrm{SO}_{4}$ dengan konduktivitas listrik.

Berdasarkan Gambar 2 dapat dilihat perbedaan bentuk dan ukuran pori untuk setiap variasi konsentrasi $\mathrm{H}_{2} \mathrm{SO}_{4}$. Pada Gambar 2(a), ukuran rata-rata diameter porinya adalah sebesar 16,3 $\mu \mathrm{m}$. Pada Gambar 2(b), ukuran rata-rata diameter pori yang diperoleh adalah sebesar 18,5 $\mu \mathrm{m}$. Pada Gambar 2(c), ukuran rata-rata diameter pori yang diperoleh sebesar 21,3 $\mu \mathrm{m}$ dan pada Gambar 2(d), ukuran rata-rata diameter pori yang diperoleh sebesar 24,6 $\mu \mathrm{m}$. Besarnya konsentrasi
TABEL I: Kandungan konsentrasi logam berat yang terkandung di dalam limbah air tambang emas sebelum dan setelah diberi karbon aktif.

\begin{tabular}{cccc}
\hline \hline $\begin{array}{c}\text { Jenis } \\
\text { Bogam } \\
\text { Berat }\end{array}$ & $\begin{array}{c}\text { Syarat } \\
\text { Batas } \\
\text { Maksimum }\end{array}$ & $\begin{array}{c}\text { Kadar Logam Berat } \\
\text { Sebelum diberi } \\
\text { karbok aktif }\end{array}$ & $\begin{array}{c}\text { Setelah diberi } \\
\text { karbon aktif }\end{array}$ \\
\hline & & & \\
$\mathrm{As}$ & 0,02 & 0,093 & 0,006 \\
$\mathrm{Ba}$ & - & 0,0455 & 0,0155 \\
$\mathrm{Cd}$ & 0,01 & 0,0455 & 0,0064 \\
$\mathrm{Cu}$ & 0,02 & 0,0325 & 0,0021 \\
$\mathrm{Hg}$ & 0,002 & 0,0856 & 0,0010 \\
$\mathrm{Mn}$ & - & 0,0455 & 0,0050 \\
$\mathrm{Se}$ & 0,01 & 0,0287 & $>0,0001$ \\
$\mathrm{Zn}$ & 0,05 & 0,228 & 0,050 \\
\hline \hline
\end{tabular}

aktivator $\mathrm{H}_{2} \mathrm{SO}_{4}$ sangat berpengaruh terhadap ukuran dan struktur pori karbon. Jelas terlihat bahwa semakin besar konsentrasi aktivator yang diberikan maka semakin besar ukuran pori yang didapatkan sehingga daya serap karbon aktif terhadap logam berat semakin besar juga. 


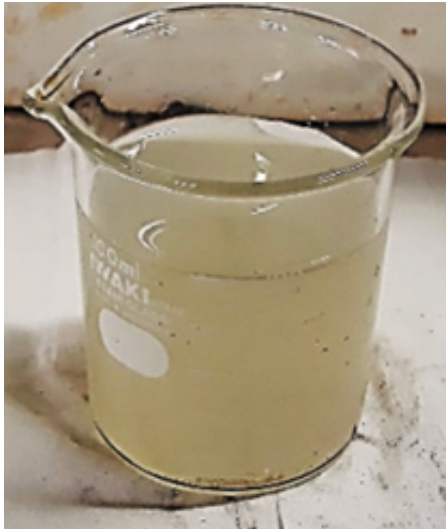

(a) $20 \%$

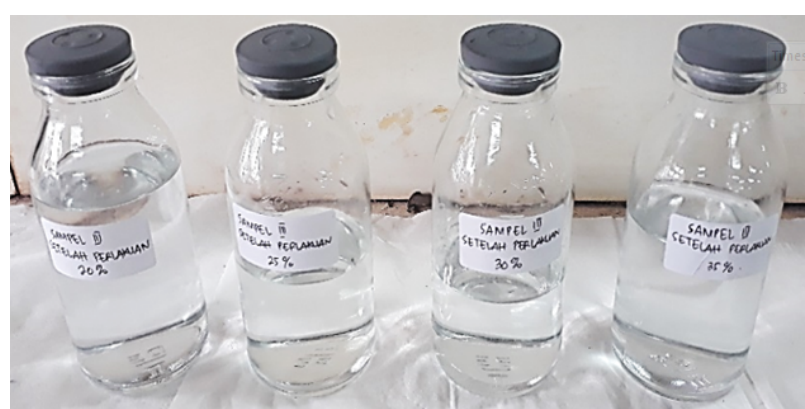

(b) $25 \%$

Gambar 4: Foto kondisi sampel sebelum dan setelah proses.

Gambar 3 merupakan plot grafik hubungan konsentrasi aktivator $\mathrm{H}_{2} \mathrm{SO}_{4}$ dengan nilai konduktivitas listrik. Berdasarkan Gambar 3 dapat dilihat hasil nilai konduktivitas listrik limbah air galian tambang emas $177,5 \mu \mathrm{S} / \mathrm{cm}$. Nilai konduktivitas listrik air yang diperoleh dengan penambahan karbon aktif konsentrasi $20 \%, 25 \%, 30 \%$,dan $35 \%$ adalah $176,7 \mu \mathrm{S} / \mathrm{cm}$, $175,5 \mu \mathrm{S} / \mathrm{cm}, 175,3 \mu \mathrm{S} / \mathrm{cm}$, dan $175,2 \mu \mathrm{S} / \mathrm{cm}$.

Semakin besar pemberian konsentrasi $\mathrm{H}_{2} \mathrm{SO}_{4}$ maka nilai konduktivitas listrik yang terhitung menjadi semakin kecil. Nilai konduktivitas ini mempengaruhi resistivitas listrik pada air karena nilai resistivitas dan nilai konduktivitas listrik meruapkan nilai yang berbanding terbalik. Jika nilai resistivitas besar maka akan semakin murni air tersebut sehingga air semakin baik untuk digunakan. Hal ini disebabkan karena pemberian variasi konsentrasi $\mathrm{H}_{2} \mathrm{SO}_{4}$ pada saat proses aktivasi mempengaruhi besarnya daya serap karbon aktif sehingga kandungan logan berat pada air dapat berkurang. Perubahan air sebelum dan sesudah ditambahkan karbon aktif dapat dilihat pada Gambar 4.

Pada Gambar 4(a) merupakan air sebelum ditambahkan karbon aktif dan Gambar 4(b) merupakan air yang telah diberikan karbon aktif. Air sebelum ditambahkan karbon aktif lebih keruh dibandingkan dengan air yang sudah diberi karbon aktif. Air yang dihasilkan menjadi jernih karena logam berat yang terkandung pada air limbah sudah diserap oleh karbon aktif.

\section{SIMPULAN}

Berdasarkan hasil dari penelitian ini dapat disimpulkan bahwa kadar logam berat yang terdapat dalam limbah air galian tambang emas berkurang setelah diberikan karbon aktif dari kulit pisang kepok. Logam berat yang terkandung di limbah air tersebut lebih banyak diserap oleh karbon aktif konsentrasi aktivator 35\% dengan pori yang lebih banyak dan ukuran rata-rata pori sebesar $24,6 \mu \mathrm{m}$. Nilai konduktivitas listrik berkurang seiring dengan peningkatan konsentrasi aktivator $\mathrm{H}_{2} \mathrm{SO}_{4}$ pada saat proses aktivasi. Nilai konduktivitas listrik yang terendah berada pada karbon aktif konsentrasi $35 \%$ sebesar 175,2 $\mu \mathrm{S} / \mathrm{cm}$ dengan $\mathrm{pH} 7$ (netral). Hasil pemurnian air yang diperoleh sudah sesuai dengan peraturan Menteri Kesehatan nomor 416/MENKES/PER/IX/1990 tentang persyaratan kualitas air bersih dan peraturan pemerintah nomor 82 tahun 2001 tentang pengelolaan kualitas air dan pengendalian pencemaran air.

\section{Ucapan Terima Kasih}

Terimakasih kepada Kemenristek Dikti yang telah membiayai penelitian ini. Terimakasih kepada Kepala Laboratorium Fisika Material, Fisika Bumi, Laboratorium Air, dan Laboratorium Metalurgi Universitas Andalas. Terimakasih kepada rekan-rekan dan dosen pembimbing yang telah membantu selama proses penelitian ini. Terimakasih kepada semua pihak terkait terutama dari Jurusan Fisika Universitas Andalas.
[1] C. Abdi, R.M. Khair, M.W. Saputra, "Pemanfaatan Limbah Kulit Pisang Kepok (Musa acuminate L.) Sebagai Karbon Aktif Untuk Pengolahan Air Sumur Banjarbaru: Fe dan Mn”, Jurnal Teknik Lingkungan, vol. 1, no. 1, hal 8-15, 2015.
[2] M.R. Adinata, "Pemanfaatan Limbah Kulit Pisang Sebagai Karbon Aktif", Skripsi, FTI, Universitas Pembangunan Nasional Veteran, Jawa Timur, 2013.

[3] I.S. Agustiani, T. Ashar, Nurmaini, "Efektivitas Karbon Ak- 
tif Sekam Padi dalam Menurunkan Mangan (Mn) Air Sumur Gali Di Desa Amplas Kecamatan Percut Sei Tuan Kabupaten Deli Serdang”, Jurnal Lingkungan dan Kesehatan Kerja (Jurnal USU), vol. 3, no. 2, hlm. 1-6, 2014.

[4] Apriyahanda, "Prinsip Kerja Konduktivitimeter", Cahaya Agung, Bandung, 2005.

[5] A. Ashraf, "Removal of Mn(II) from Water Using Chemically Modified Banana Peels as Efficient Adsorbent", J. Environtmental Nanotechnology, vol. 7, pp. 57-63, 2017.

[6] L.K. Bakiya, P.N. Sudha, "Adsorption of Copper (II) Ion onto Chitosan/Sisal/Banana Fiber Hybrid Composite", J. Environ., vol. 3, pp. 453, 2012.

[7] R.S.D. Castro, L. Caetano, G. Ferreira, P.M. Padilha, M.J. Saeki, L.F. Zara, M. Antonio, and G.R. Castro, ”Banana Peel Applied to The Solid Phase Extraction of Copper and Lead from River Water Preconcentration of Metal Ions with A Fruit Waste", Industrial \& Engineering Chemistry Research, vol. 50, no. 6, pp. 3446-3451, 2011. (Retrieved from ubs.acs.org/IECR).

[8] Connel and Miller, "Kimia dan Etoksikologi Pencemaran", UI Press, Jakarta, 1995.

[9] Darmono, "Logam Dalam Sistem Biologi Makhluk Hidup", UI Press, Jakarta, 1995.

[10] F. Gultom, "Pengaruh Konsentrasi $\mathrm{H}_{2} \mathrm{SO}_{4}$ Terhadap Kualitas Karbon Aktif dari Kulit Durian sebagai Adsorben Logam Cu", Skripsi, Politeknik Negeri Sriwijaya, Palembang, 2012.

[11] L. Hasibuan, "Studi Penggunaan Karbon Aktif dari Kulit Durian untuk Meningkatkan Kualitas Minyak Jelantah", Skripsi, Universitas Andalas, Padang, 2008.

[12] E. Hewwet, A. Stem, and Mrs. Wildfong, "Banana Peel Heavy
Metal Water Filter”, 2011 (http://users.wpi.ed,.diakses 13 April 2017).

[13] Isroi, "Pupuk Limbah Padat Organik", 2009 (http://isroi @ paid.com,.diakses 14 April 2017).

[14] N. Kurniati, "Pengaruh Konsentrasi Aktivator Kimia Asam Klorida dan Kalium Hidroksida Terhadap Kualitas Karbon Aktif dari Bambu", Skripsi, Politeknik Negeri Sriwijaya, Palembang, 2011.

[15] Miettinen, "Inorganic Trace Element as Water Pollutan to Health and Aquatic Biota", Academy Press, New York, 1997.

[16] W. Mardhatillah, "Penentuan Konsentrasi Logam Berat Pb, Cu, Zn, dan Konduktivitas Listrik Limbah Cair Metode Batch dan Metode Kontinyu", Agrointek, vol. 5, no. 2, hal 142-145, 2008.

[17] A.O. Opeyemi, S.O. Maurice, "Application of Banana Peels Nanosorbent for The Removal of Radioactive Minerals from Real Mine Water", Journal of Environmental Radioactivity, Vol. 164, pp. 369-376, 2006.

[18] H. Razak, "Pengaruh Logam Berat Terhadap Lingkungan", Pewarta Oseana, Jakarta, LON-LIPI, 1980.

[19] C. Sitanggang, "Pemanfaatan Arang Sekam Padi Sebagai Adsorben untuk Menurunkan Kadar Besi (Fe) dalam Air Sumur", Skripsi. Universitas Sumatera Utara, Medan, 2010.

[20] U. Suriawiria, "Air Dalam Kehidupan dan Lingkungan yang Sehat", Edisi Pertama, Erlangga, Bandung, 1996.

[21] M.M. Ulfia Suci, "Sintesis Karbon Aktif dari Kulit Pisang untuk Pemurnian Air Gambut", Jurnal Fisika Unand, vol. 3, no. 4, hlm. 255-261, 2014. 